\title{
Optimization of Enzymatic Pretreatment for the Production of Fermented Ginseng using Leaves, Stems and Roots of Ginseng
}

\author{
Kyunglae Cho' ${ }^{1}$ Hye Jin Woo', In Sook Lee ${ }^{2}$, Jun Won Lee, \\ Young Cheol $\mathrm{Cho}^{3}$, Il Nam Lee ${ }^{4}$ and Hee Jeong Chae ${ }^{1 *}$ \\ ${ }^{1}$ Department of Food and Biotechnology and Center for Food Function and Safety, Hoseo University, Asan 336-795, Korea \\ ${ }^{2}$ Gimpo-City Agricultural Technology Center, Gimpo 415-743, Korea \\ ${ }^{3}$ Gyeonggi Agricultural Research and Extension Services, Hwasung 445-784, Korea \\ ${ }^{4} R \& D$ Center, Nu-Pharm, Co., Ltd, Gimpo 415-855, Korea
}

(Received January 18, 2009; Revised February 4, 2009; Accepted February 6, 2009)

\begin{abstract}
This study sought to optimize the extraction and enzymatic treatment conditions of Panax ginseng leaves, stems, and roots for the production of fermented ginseng. The optimization enhanced the extraction of total saccharide, a nutrient and growth-activating factor for Lactobacillus bacteria. The hydrolysis of ginseng leaves, stems, and roots was tested with eight enzymes (Pentopan, Promozyme, Celluclast, Ultraflo, Pectinex, Ceremix, Viscozyme, and Tunicase). The enzymatic hydrolysis conditions were statistically optimized by the experimental design. Optimal particle size of ginseng raw material was $<0.15 \mathrm{~mm}$, and optimal hydrolysis occurred at a $\mathrm{pH}$ of $5.0-5.5$, a reaction temperature of $55-60^{\circ} \mathrm{C}$, a Ceremix concentration of $1 \%$, and a reaction time of $2 \mathrm{hr}$. Ceremix produced the highest dry matter yield and total saccharide extraction. Ginseng leaves were found to be the most suitable raw material for the production of fermented ginseng because they have higher carbohydrate and crude saponin contents than ginseng roots
\end{abstract}

Key words : enzyme treatment, ginseng, leaves, stems, roots

\section{INTRODUCTION}

Korean ginseng belongs to the Panax genus in the family Araliaceae. It grows primarily in northern China, Korea, and eastern Siberia and is a popular herbal remedy that has been used in Asia for several thousand years. Studies have demonstrated the beneficial effects of ginseng in treatment of diabetes [1], the central nervous system [2], cancer [3], the immune system [4], blood pressure [5], inflammation [6], and allergies [7, 8]. Saponins (ginsenosides) are considered to be the main active polysaccharide component of ginseng, and more than 40 ginsenosides have been identified [9-11]. Non-saponin physiological components of ginseng include polyacetylene, phenolic compounds, acidic polysaccharides, peptides, and alkaloids [9-11]. Human health is increasingly threatened by factors related to industrialized civilization, environmental pollution, increased income, rising standards of living, overnutrition, and increased fat intake. Health foods and

* Corresponding author. E-mail: hjchae@hoseo.edu Phone: +82-41-540-5642, Fax: +82-41-532-5640 herbal medicines have therefore attracted increasing attention.

Recent studies have employed new technologies to maximize the herbal benefits of ginseng, and have focused on the development of new ginseng health products [12-14]. Fermented ginseng has received particular attention because it contains structurally modified ginsenosides that enhance the herb's beneficial effects. Structural modifications can be achieved with treatments that employ heat [15,16], mild acids [17,18], alkalines [3,19], and micro-organic enzymes. For example, ginsenoside $\mathrm{Rb} 1$ has been transformed to $\mathrm{Rd}$ in Rhizopus $s p$. with enzyme treatment [20], ginsenoside $\mathrm{Rb}_{1}$ has been hydrolyzed by $\beta$-glucosidases from human intestinal bacteria $[21,22]$, gypenoside- 5 has been hydrolyzed into Rd by gypenoside- $\alpha$-L-rhamnosidase [23], and the ginsenosides $\mathrm{Re}$ and $\operatorname{Rg} 1$ have been hydrolyzed by lactase from Penicillium $s p$. into 20(S)-ginsenoside $\mathrm{Rh}_{1}$ [6-O-beta-D-glucopyranosyl-20(S)-protopanaxatriol] [24]. Dammarane-type triterpenoid skeletons in ginseng saponins can be modified by saccharides such as glucose, arabinose, and xylose, producing various saponins depending on the method of 
modification.

The active compounds in orally administered ginseng must be degraded in the digestive system to yield the desired pharmacological effects. Polysaccharides obtained from the plant can be metabolized by the enzymes of human intestinal bacteria such as Lactobacillus [25], but not by human digestive enzymes. Furthermore, the active compounds in ginseng are not simply saponins, but saponin metabolites hydrolyzed by intestinal bacteria [25]. The metabolic pathway and absorption rate of ginseng saponins therefore depend on various factors of the intestinal bacteria [26]. Bacterial or enzymatic transformation of saponin can be induced by a process in which bacterial â-glucosidase hydrolyzes the saccharides of saponin. Each bacterial hydrolytic enzyme is characterized by a specific saponin substrate and preferred cleavage site [27].

Unfortunately, most studies of ginseng leaves and stems, the by-products of ginseng processing, have been limited to the simple analysis of ginsenoside content and nutritional factors $[28,29]$. Some recent studies, however, have focused on the pharmacological effects of compounds in ginseng leaves and stems. This research has revealed that ginseng leaves have a higher saponin content than that of the roots ( $\sim 4$ to 5 times) and stems (>9 times) [30-33]. The efficient use of these ginseng by-products has therefore become a matter of interest. Fermented ginseng production has traditionally used only the roots, but we expect that the leaves and stems may also be very useful. Treatment of enzymes before fermentation may also improve the efficiency of fermented ginseng production.

The production of fermented ginseng has primarily employed Lactobacillus, which has important nutritional requirements. The components in ginseng must be hydrolyzed to allow their efficient uptake as a nutritional source. The present study thus aimed to optimize hydrolysis conditions to maximize the extraction of total saccharide in the leaves, stems, and roots of ginseng.

\section{MATERIALS AND METHODS}

\section{Ginseng and reagents}

The leaves, stems, and roots of 6-year-old Panax ginseng plants were provided by the Gimpo Agricultural Technology Center (Gimpo-si, Gyeonggi-do, Korea). Pentopan, Promozyme, Celluclast, Ultraflo, Pectinex, Ceremix, and Viscozyme carbohydrate hydrolases were purchased from Nordisk A/S (Copenhagen, Denmark), and Tunicase of Athrobacter sp. ATCC 21712 was obtained from
Diawa Kasei (Okazaki, Japan). All other reagents used in this study were of analytical grade.

\section{Determination of the contents of proximate com- positions and crude saponin}

The contents of proximate compositions (i.e., moisture, ash, crude lipid, crude protein, and crude fiber) were determined according to recommended protocols in the 'Food Code' [34], using the air-oven method, dry ashing Soxhlet extraction, the semimicro-Kjeldahl method with a 6.25 nitrogen coefficient [35], and the Henneberg-Stohmann method, respectively. Carbohydrate content was then calculated by subtracting the sum of crude protein, total fat, moisture, and ash from the total weight of the sample. Crude saponin content was measured using the analytical protocol for red ginseng compounds described in the 'Food Code' [34]. Each $5 \mathrm{~g}$ sample of ginseng leaves, stems, and roots was suspended in $50 \mathrm{ml}$ of water-saturated butanol. Extraction was performed three times at $85^{\circ} \mathrm{C}$ for $1 \mathrm{hr}$ in a water bath (SWB-10, Jeio Tech, Korea). All extracts were combined and centrifuged at 3,200 rpm $(1,969 \mathrm{x} \mathrm{g})$ for $10 \mathrm{~min}$ using a Union $55 \mathrm{R}$ centrifuge (Hanil, Korea). Distilled water $(50 \mathrm{ml})$ was added to the supernatant, and the mixture was incubated at room temperature for $6 \mathrm{hr}$. After removing the water layer, extracts in the water-saturated butanol were concentrated with a vacuum evaporator at $80^{\circ} \mathrm{C}$. Ether $(50 \mathrm{ml})$ was added to the extracts and they were incubated at $46^{\circ} \mathrm{C}$ for $30 \mathrm{~min}$. The extracts were then dried at $105^{\circ} \mathrm{C}$ for $20 \mathrm{~min}$, and dry weight was measured to calculate the crude saponin content.

\section{Enzymatic treatment}

Ginseng leaves, stems and roots were pulverized using a KT-34 machine (Korea Medi Co., Ltd., Korea), and separated by particle size $(<0.15 \mathrm{~mm}, 0.15-0.18 \mathrm{~mm}$, and $0.18-0.28 \mathrm{~mm}$ ). Distilled water containing $6 \%(\mathrm{w} / \mathrm{v})$ pulverized ginseng was mixed with $1 \%(\mathrm{w} / \mathrm{w})$ polysaccharide hydrolase, and incubated at $40-50^{\circ} \mathrm{C}$ for $2 \mathrm{hr}$ in a water bath (SWB-10). After enzymatic hydrolysis, the mixture was centrifuged at $3,200 \mathrm{rpm}(1,969 \mathrm{x} \mathrm{g})$ for $15 \mathrm{~min}$ using a Union 55R centrifuge, and the dry matter yield and total saccharide in the supernatant were determined. The characteristics of the eight carbohydrate hydrolases used in this study are summarized in Table 1.

\section{Experimental design to optimize extraction}

To optimize the enzymatic hydrolysis conditions for extracting total saccharide from ginseng leaves, stems, 
Table 1. Characteristics of the enzymes used for the hydrolysis of ginseng leaves, stems, and roots

\begin{tabular}{|c|c|c|c|c|}
\hline \multirow{2}{*}{ Enzyme } & \multirow{2}{*}{ Type } & \multirow{2}{*}{ Enzyme characterization } & \multicolumn{2}{|c|}{ Optimum conditions } \\
\hline & & & $\mathrm{pH}$ & Temp $\left({ }^{\circ} \mathrm{C}\right)$ \\
\hline Pentopan & Mono & Xylanase & 5.5 & 55 \\
\hline Promozyme & Mono & Pullulanase & 5.5 & 55 \\
\hline Cellulclast & Mono & Cellulase & 5.0 & 55 \\
\hline Ultraflo & Complex & $\begin{array}{l}\beta \text {-glucanase, cellulase xylanase, } \\
\text { pentosanase, arabanase }\end{array}$ & 6.5 & 60 \\
\hline Pectimex & Complex & $\begin{array}{l}\text { pectin transeliminase, } \\
\text { cellulase hemicellulase, polygalacturonase }\end{array}$ & 5.0 & 55 \\
\hline Ceremix & Complex & $\begin{array}{c}\beta \text {-glucanase, cellulase, } \\
\text { pentosanase proteinase, } \alpha \text {-amylase }\end{array}$ & 5.0 & 60 \\
\hline Viscozyme & Complex & $\begin{array}{c}\beta \text {-glucanase, cellulase hemicellulase, } \\
\text { zylanase, arabanase }\end{array}$ & 5.0 & 50 \\
\hline Tunicase & Mono & $\beta$-glucanase & 7.0 & 50 \\
\hline
\end{tabular}

and roots, we formulated an experimental design based on the central composite design of the response surface method (RSM) using Design Expert 6.0 software (Statease Inc., MN, USA).

\section{Determination of dry matter yield and total sac-} charide

Dry matter yields in the hydrolase-treated extracts of ginseng leaves, stems, and roots were determined using a refractometer (Model N.O.W. 507-1, Nippon Optical Works, Tokyo, Japan). Total saccharide was determined with the phenol-sulfuric acid method [36]. Briefly, $0.6 \mathrm{ml}$ of ginseng extract was mixed with $0.3 \mathrm{ml}$ of $5 \%$ phenol and $1.5 \mathrm{ml}$ of concentrated sulfuric acid, and incubated at $85^{\circ} \mathrm{C}$ for $30 \mathrm{~min}$ in a water bath (SWB-10). After cooling to room temperature for $5 \mathrm{~min}, 0.2 \mathrm{ml}$ of the mixture was transferred to a 96-well plate, and absorbance was measured at $490 \mathrm{~nm}$ using a Versa Max microplate reader (Molecular Devices, CA, USA). Standard curves were obtained by using D-glucose as a reference standard for colorimetric analysis.

\section{RESULTS AND DISCUSSION}

\section{Determination of the contents of proximate com- positions and crude saponin}

Proximate composition and crude saponin contents were determined for the leaves, stems, and roots of 6year-old ginseng plants cultivated in Gimpo, Korea. The total carbohydrate content of ginseng leaves was $69.0 \%$, that of stems was $82.6 \%$, and that of roots was $80.2 \%$ (Table 2). Kim et al. [37] analyzed the leaves, stems and roots of 6-year-old ginseng plants cultivated in the Jeung Pyeong open test field of the KT \& G Central Research Institute, finding total carbohydrate contents of $55.4 \%$, $36.1 \%$, and $65.9 \%$, respectively. Our results show that each ginseng element may contain much higher carbohydrate levels than those found by Kim et al. [37]. We found a much higher crude saponin content in ginseng leaves $(24.8 \%)$ than in stems $(4.6 \%)$ and roots $(5.3 \%)$, also inconsistent with the results of Kim et al. [37] (Table 3). Furthermore, Chang et al. [33] reported that dry ginsengleaf tea contained high levels of crude saponin, ranging from $6.86 \%$ to $7.5 \%$ depending on the manufacturing pro-

Table 2. Approximate compositions of ginseng leaves, stems, and roots

(dry basis, \%)

\begin{tabular}{cccc}
\hline \hline Components & Leaves & Stems & Roots \\
\hline Carbohydrate & $69.0 \pm 0.04$ & $82.6 \pm 0.02$ & $80.2 \pm 0.05$ \\
Crude protein & $15.5 \pm 0.06$ & $8.1 \pm 0.06$ & $12.5 \pm 0.04$ \\
Crude lipid & $5.4 \pm 0.13$ & $1.2 \pm 0.04$ & $2.0 \pm 0.01$ \\
Crude ash & $10.0 \pm 0.05$ & $8.0 \pm 0.06$ & $5.5 \pm 0.05$ \\
\hline
\end{tabular}

Table 3. Crude saponin content (total oligosaccharide) of ginseng leaves, stems, and roots

(dry basis, \%)

\begin{tabular}{cccc}
\hline \hline Components & Leaves & Stems & Roots \\
\hline Crude saponin & 24.8 & 4.6 & 5.3 \\
Total oligosaccharide & 0.9 & 2.0 & 3.2 \\
\hline
\end{tabular}


cess. Our findings clearly show that ginseng leaves contain high amounts of carbohydrates and crude saponin, and also suggest that the leaves may be a better source for fermented ginseng produced by enzymatic treatment and Lactobacillus. We therefore investigated the use of ginseng leaves in the production of fermented ginseng.

\section{Effects of enzyme treatment on total saccharide extraction}

To optimize the concentration of a ginseng source for enzyme treatment, we determined the crude polysaccharide and total carbohydrate contents obtained from various concentrations of ginseng leaves, stems, and roots. Tark et al. [38] extracted high amounts of saccharide from a concentrated ginseng source, although the yield of this extraction was remarkably decreased. Our study also confirmed that the extraction of crude saccharide varied in direct relation to the concentration of ginseng leaves, stems, and roots (data not shown). Total saccharide extraction was maximized with a $6 \%$ concentration, but did not increase with concentrations $>6 \%$ (data not shown).
To optimize conditions for total saccharide extraction from ginseng leaves, stems, and roots, pulverized ginseng was incubated at $50^{\circ} \mathrm{C}$ for $2 \mathrm{hr}$ with eight different carbohydrate hydrolases [final conc. 1\% (v/v)]. After the hydrolytic process, microwave treatment was performed for 4 min, and dry matter yield and total saccharide extraction were determined (Fig. 1). The highest dry matter yield was obtained with Ceremix ( $\beta$-glucanase, cellulase, pentosanase, protensase, and $\alpha$-amylase), although this difference was not statistically significant. Ceremix increased the total saccharide yield more than 1.4-, 1.7-, and 2.2fold (vs. control group) in ginseng leaves, stems, and roots, respectively.

To investigate whether particle size affected dry matter yield and total saccharide extraction, ginseng root samples with different particle sizes were divided into two groups. One set of samples was treated with Ceremix and the other was left untreated as a control. Ceremix treatment increased the total saccharide yield about two-fold in ginseng roots. Particle size did not significantly affect yield in either the Ceremix or control group (Fig. 2). The dry
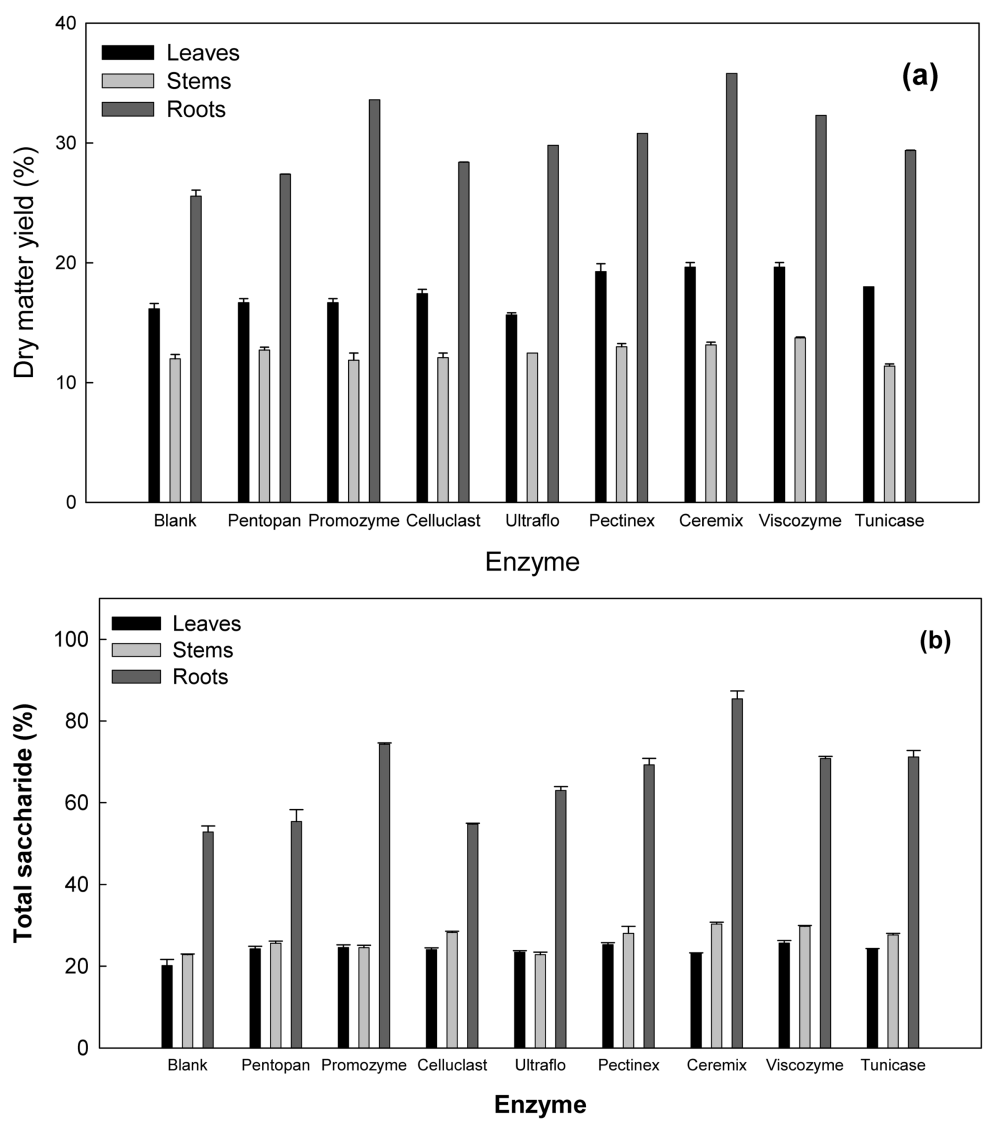

Fig. 1. The effects of enzyme type on dry matter yield (a) and total saccharide extraction (b) from ginseng leaves, stems, and roots. 

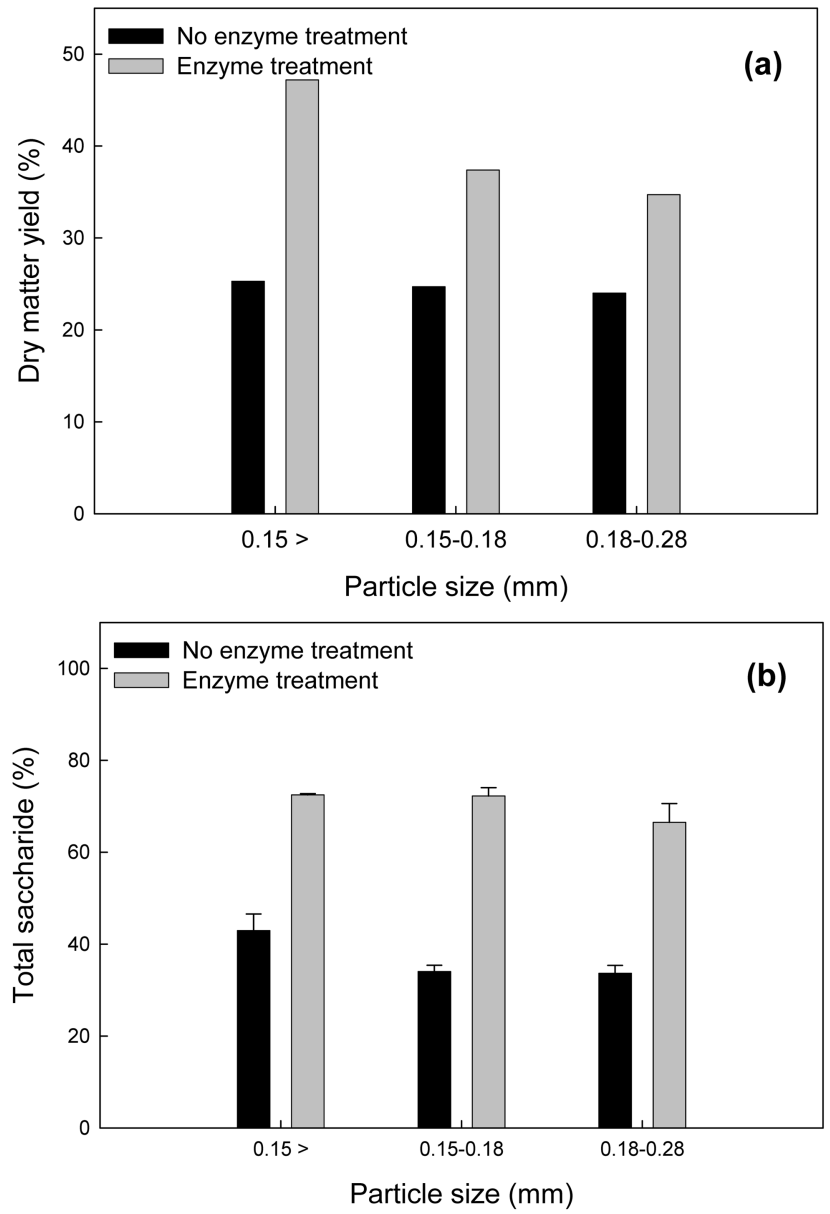

Fig. 2. The effects of ginseng particle size on dry matter yield (a) and total saccharide extraction (b) from ginseng roots.

matter yields of Ceremix-treated ginseng roots with particle sizes of $0.18-0.28 \mathrm{~mm}, 0.15-0.18 \mathrm{~mm}$, and $<0.15 \mathrm{~mm}$ were $34.7 \%, 37.4 \%$, and $47.2 \%$, respectively (Fig. 2). Control samples with corresponding particle sizes had dry matter yields of $24.0 \%, 24.7 \%$, and $25.3 \%$, respectively (Fig. 2). Small particle size $(<0.15 \mathrm{~mm})$ may thus increase dry matter yields. These results are consistent with those of Cho et al. [39], who showed that the use of red ginseng powder reduced extraction time and increased extraction yield.

We also investigated the effects of extraction time and Ceremix concentration on dry matter yield and total saccharide extraction. Pulverized ginseng leaf, root, and stem samples with small particle sizes $(<0.15 \mathrm{~mm})$ were suspended in distilled water [final conc. $6 \%(\mathrm{w} / \mathrm{v})$ ] and incubated with different concentrations of Ceremix $(0 \%$, $0.25 \%, 0.5 \%$, and $1 \%$ ) at $50^{\circ} \mathrm{C}$ for up to $6 \mathrm{hr}$. The ginseng mixture was centrifuged every hour after enzyme treatment, and the supernatant was used to calculate dry matter
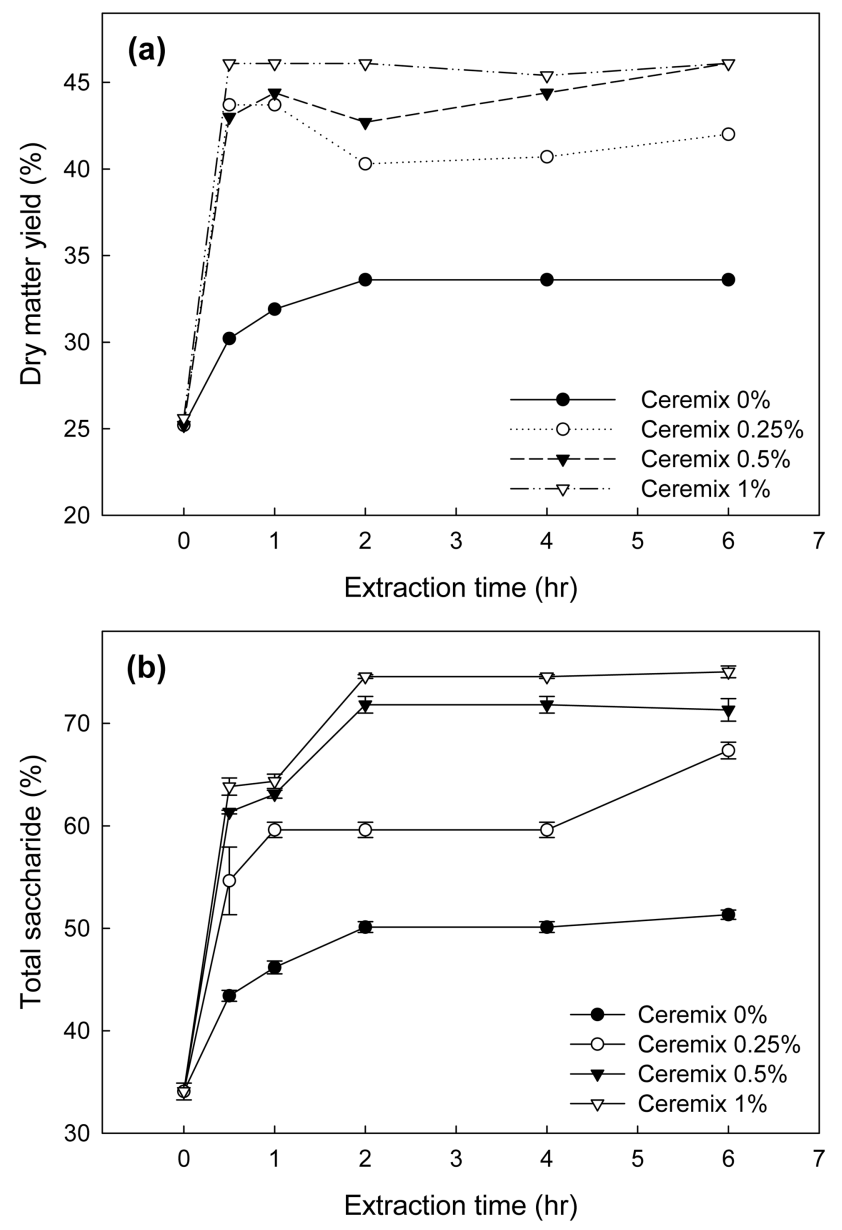

Fig. 3. The effects of extraction time and Ceremix concentration on dry matter yield (a) and total saccharide extraction (b) from ginseng leaves, stems, and roots.

yield and total saccharide extraction. At an extraction time of $1 \mathrm{hr}$, the sample treated with $1 \%(\mathrm{w} / \mathrm{w})$ Ceremix produced a $25 \%$ dry matter yield and a $35 \%$ total saccharide extraction. An additional $1 \mathrm{hr}$ of extraction time significantly increased both dry matter yield (46\%) and total saccharide extraction (64\%) (Fig. 3), but further extraction time did not produce additional increases. While overall yield may initially be related to extraction time, longer extraction time does not necessarily increase the efficiency of the process. In fact, Lee et al. [40] showed that two to three repetitions of a 1-2 hr extraction time may produce the most efficient yield. Based upon our results, we set a single 2-hr extraction time for the following experiments.

\section{Experimental design to optimize extraction}

We used an RSM-generated model to investigate the 
Table 4. Response surface central composite design for the enzymatic hydrolysis of ginseng leaves, stems, and roots

\begin{tabular}{cccccc}
\hline \hline Factor & Parameter & Level & Low Level & High Level & Standard Deviation \\
\hline $\mathrm{A}$ & Temperature & 45 & 30 & 60 & 0 \\
$\mathrm{~B}$ & $\mathrm{pH}$ & 5 & 4 & 6 & 0 \\
$\mathrm{C}$ & Enzyme concentration & 1 & 0.5 & 1.5 & 0 \\
\hline
\end{tabular}

(a)

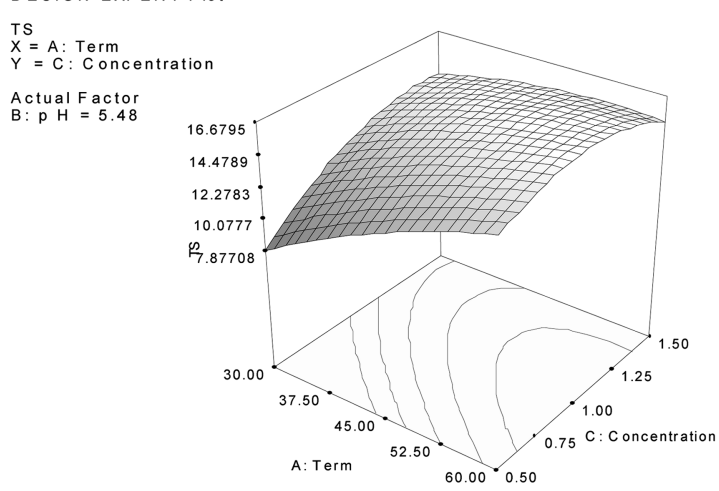

(b)

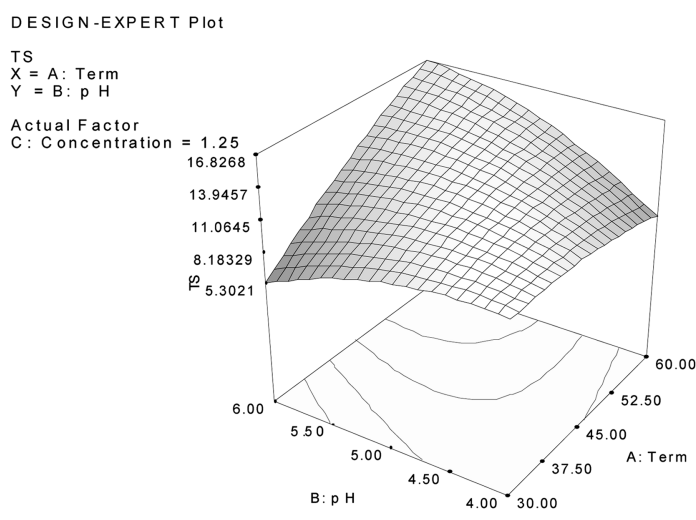

(c)

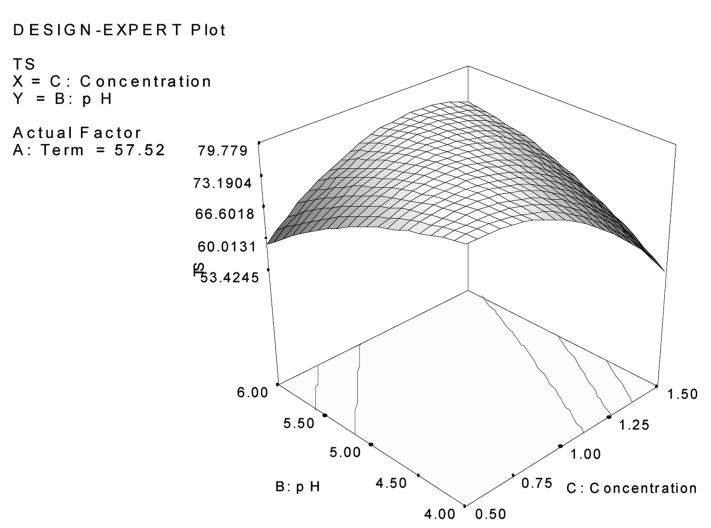

Fig. 4. Response surface for total saccharide recovery as a function of extraction temperature $\left(\mathrm{X}_{1}\right)$, enzyme concentration $\left(\mathrm{X}_{2}\right)$, and $\mathrm{pH}\left(\mathrm{X}_{3}\right)$ using ginseng leaves (a), stems (b), and roots (c).

optimal conditions for extracting total saccharide from ginseng leaves, stems, and roots. Extraction temperature
$\left(\mathrm{X}_{1}, 30-60^{\circ} \mathrm{C}\right)$, Ceremix concentration $\left(\mathrm{X}_{2}, 0.5-1.5 \%\right)$, and $\mathrm{pH}$ of the extracting solution $\left(\mathrm{X}_{3}, 4-6\right)$ were treated as dependent variables, while total saccharide was the independent variable (Table 4). Analysis of variance (ANOVA) was used to examine the interaction between dependent and independent variables (Fig. 4). The total saccharide extracted from ginseng leaves was $11.10-16.78 \%$, that extracted from stems was $6.04-13.58 \%$, and that extracted from roots was $48.44-75.73 \%$. A Ceremix concentration of $1 \%(\mathrm{w} / \mathrm{w})$, extracting solution $\mathrm{pH}$ of $5.0-5.5$, and extracting temperature of $55-60^{\circ} \mathrm{C}$ were identified as the optimum conditions of enzymatic pretreatment.

In summary, this study showed that Ceremix was the most efficient of the eight carbohydrate hydrolases we tested for the extraction of total saccharide from ginseng leaves, stems, and roots. We optimized the Ceremix treatment conditions for the production of fermented ginseng. However, the effects of this optimized pre-treatment process on Lactobacillus fermentation and the overall efficiency of the fermented ginseng production process should be further evaluated in future studies.

\section{ACKNOWLEDGEMENTS}

The present study was financially supported by research grants, '2008 Collaborative Research Projects for Agricultural Science and Technology' from Rural Development Administration, and Ministry of Education, Science Technology(MEST), and Korea Institute for Advancement of Technology(KIAT) through the Human Resource Training Project for Regional Innovation.

\section{REFERENCES}

1. Elma ZT, Ilian EZ, Christina IH. Effect of ginsenoside Rg1 on insulin binding in mice liver and brain membrane. Phytother Res. 5: 46-48 (1991)

2. Attle AS, Wu JA, Yuan CS. Ginseng pharmacology: multiple constituents and multiple action. Biochem Pharmacol. 58: 1685-1693 (1999)

3. Im KS, Chung HY, Park SH, Je NK. Anticancer effect of the hydrolyzed monogluco-ginsenoside of total saponin from ginseng leaf. Korean J Ginseng Sci. 19: 291-294 (1995) 
4. Kim MJ, Jung NP. The effect of ginseng saponin on the mouse immune system. Korean J Ginseng Sci. 11: 130-135 (1987)

5. Kang SY, Kim ND. The antihypertensive effect of red ginseng saponin and the endothelium derived vascular relaxation. Korean J Ginseng Sci. 16: 175-182 (1992)

6. Wu JY, Gardner BH, Murphy CI, Seals JR, Kensil CR, Recchia J, Beltz GA, Newman GW, Newman MJ. Saponin adjuvant enhancement of antigen-specific immuneresponses to an experimental HIV-1 vaccine. J Immunol. 148: 1519-1525 (1992)

7. Bae EA, Cho MK, Park EK, Park SY, Shin HY, Kim DH. Metabolism of ginsenoside Rc by human intestinal bacteria and its related antiallergic activity. Biol Pharm Bull. 25: 743747 (2002)

8. Park EK, Cho MK, Han MJ, Kim DH. Antiallergic and antiinflammatory activities of ginsenoside $\mathrm{Rh}_{1}$. Int Arch Allergy Immunol. 133: 113-120 (2004)

9. Shibata S, Tanaka O, Soma K, Iita Y, Ando Y, Nakamura H. Studies on saponins and sapogenins of ginseng, the structure of panaxatriol. Tetra Lett. 3: 207-213 (1965)

10. Shibata S. Some chemical studies on ginseng. In: Proceedings of International Ginseng Symposium, The Korean Society of Ginseng, Seoul, 1: 69-76 (1974)

11. Namba T. The encyclopedia of wakan-yaku(traditional sinoJapanese medicines) with color pictures. Hoikusha, Osaka, Japan 1: 50-51 (1993)

12. Choi YE, Jeong JH. Recent progress of ginseng biotechnology and progress toward food application. J Food Ind Nutr. 8: 24-29 (2003)

13. Lee BY. Status of Korean ginseng industry and development of new ginseng products. J Food Ind Nutr. 8: 1-9 (2003)

14. Park S, Cho YJ, Pyee J, Hong HD. Meta-analysis of studies and patents on Korean ginseng in recent 5 years in Korea and prospective needs. J Ginseng Res. 30: 212-219 (2006)

15. Kitagawa I, Yoshikawa M, Yoshihara M, Hayashi T, Taniyama. Chemical studies on crude drug procession. I, on the constituents of ginseng radix rubura (I). Yakugaku Zasshi 103: 612622 (1983)

16. Park JH. Sun ginseng-a new processed ginseng with fortified activity. J Food Ind Nutr. 9: 23-27 (2004)

17. Han BH, Park MH, Han YN, Woo LK, Sankawa U, Yahara S, Tanaka O. Degradation of ginseng saponins under mild acidic conditions. Planta Medica. 44: 146-149 (1982)

18. Bae EA, Han MJ, Kim EJ, Kim DH. Transformation of ginseng saponins to ginsenoside $\mathrm{Rh}_{2}$ by acids and human intestinal bacteria and biological activities of their transformants. Arch Pharm Res. 27: 61-67 (2004)

19. Chen Y, Nose M, Ogihara Y. Alkaline cleavage of ginsenosides. Chem Pharm Bull. 35: 1653-1655 (1987)

20. Kim SD, Do JH, Lee JC. Effect of red ginseng residue on various enzyme production of alcohol fermentation koji. Korean J Ginseng Sci. 6: 131-137 (1982)

21. Bae EA, Park SY, Kim DH. Constitutive $\beta$-glucosidases hydrolyzing ginsenoside $\mathrm{Rb}_{1}$ and $\mathrm{Rb}_{2}$ from human intestinal bacteria. Biol Pharm Bull. 23: 1481-1485 (2000)

22. Park SY, Bae EA, Sung JH, Lee SK, Kim DH. Purification and characterization of ginsenoside $\mathrm{Rb}_{1}$-metabolizing $\beta$-glucosidase from fusobacterium K-60, a human intestinal anaerobic bacterium. Biosci Biotechnol Biochem. 65: 1163-1169 (2001)

23. Yu H, Liu H, Zhang C, Tan D, Lu M, Jin F. Purification and characterization of gypenoside- $\alpha$-L-rhamnosidase hydrolyzing gypenoside-5 into ginsenoside Rd. Process Biochem. 39: 861-867 (2004)

24. Ko SR, Suzuki Y, Choi KJ, Kim YH. Enzymatic preparation of genuine prosapogenin, 20(S)-ginsenoside Rh1, from ginsenosides Re and $\operatorname{Rg}_{1}$. Biosci Biotechnol Biochem. 64: 27392743 (2000)

25. Hasegawa H, Sung JH, Matssumiya S, Uchiyama M. Main ginseng saponin metabolites formed by intestinal bacteria. Planta Med. 62: 453-457 (1996)

26. Hasegawa H, Sung JH, Benno Y. Role of human intestinal prevotella oris in hydrolyzing ginseng saponins. Planta Med. 63: 436-440 (1997)

27. Suzuk, Y, Ko SR, Choi KJ, Uchida K, Lee YG, Kim YH. Enzymatic glycosylation and hydrolysis of ginseng saponins. In: Proceedings of International Ginseng Symposium, The Korean Society of Ginseng, Seoul, 7: 373-374 (1988)

28. Choi KJ, Kim MW, Kim DH. Fatty acid compositions of the various parts of ginseng plant. Korean J Food Nutr. 12: 357363 (1983)

29. Park H, Park HS, Hong JU. Effect of high temperature Panax ginseng leaf. J Korean Agric Chem Soc. 29: 336-371 (1986)

30. Zhang S, Takeda T, Zhu T, Yao X, Tanaka Y, Okihara Y. A new minor saponin from the leaves of Panax ginseng. Planta Med. 56: 298-301 (1990)

31. Lee JW, Do JH. Antioxidative activity of ethanol extraction fraction from the Korean red tail ginseng. Korean J Food Sci Technol. 33: 497-500 (2001)

32. Zhang S, Yao X, Chen Y, Cui C, Tezuka T, Kikuchi T. Ginsenoside la, a novel saponin from the leaves of Panax ginseng. Chem Pharm Bull. 37: 1966-1968 (2001)

33. Chang HK. Effect of processing methods on the saponin contents of Panax ginseng leaf-tea. Korean J Food Nutr. 16: 4653 (2003)

34. KFIA. Food code. Korea Association Food Industry, Seoul, p 585-624 (2006)

35. Chae SG, Kang KS, Ma SJ, Bang KU, Oh MH, Oh SH. Analysis of Food. Jigu Publishing, Seoul, p 270-275 (2000)

36. Dubois M, Gillers KA, Hamilton JK, Rebers PA, Smith J. Colorimetric method for determination of sugar and related 
substance. Anal Chem. 28: 350-352 (1956)

37. Kim HJ, Jo JS, Nam SH, Park SH, Mhee KC. Free sugar distribution in ginseng plant and change of it's content in the root with dehydration. Korean J Ginseng Sci. 7: $44-50$ (1987)

38. Tark K, Cho K, Park KH, Son S M, Chae HJ. Optimization of extraction conditions for polysaccharide using red ginseng marc. J Ginseng Res. 33: 337-342 (2009)
39. Cho CW, Kim SW, Rho J, Rhee YK, Kim K. Extraction characteristic of saponin and acidic polysaccharide based in the red ginseng particle size. J Ginseng Res. 32: 179-186 (2008)

40. Lee JW, Do JH. Extraction condition of acidic polysaccharide from Korean red ginseng marc. J Korea Ginseng Res. 26: 202-205 (2002) 